\title{
THE EVOLUTION OF E-HEALTH - MOBILE TECHNOLOGY AND MHEALTH
}

\author{
Dr Chandrashan Perera MBBS ${ }^{1,2}$ \\ ${ }^{1}$ Editor-In-Chief, Journal of Mobile Technology in Medicine, ${ }^{2}$ Austin Hospital, Melbourne, Australia \\ Corresponding Author: editor@journalmtm.com \\ Journal MTM 1:1:1-2, 2012 \\ doi:10.7309/jmtm.1
}

Medicine has always been an information intensive field from the first days of practice, when pearls of wisdom were passed along the generations as word of mouth. Throughout history, informatics has been an integral part of medicine, facilitating the storage and accession of vast amounts of data. This has come to the culmination of present day medical practice, which is built on the foundations of Electronic-Health (E-Health). New information is rapidly disseminated through electronic access to medical journals and other relevant sources of information. Patient data is increasingly stored electronically, and reference information including textbooks are stored electronically in websites. The E-Health revolution digitized the world, and medicine has benefited immensely. Whilst having this information available electronically has numerous benefits, the delivery of this information to medical staff has been less than ideal, requiring doctors to be tied down to devices such as immobile desktop computers. The next stage in digital informatics is to gain rapid access in both storing and creating material in a convenient manner; and smartphones have been an instrumental tool in this evolution.

Smartphones have a number of characteristics which give them an advantage over other technologies, such as portability, constant internet connectivity, enough computing power to run complex applications and the simple fact that the majority of doctors have one in their pocket. In June 2011, the penetration of wireless devices amongst the US population was recorded at $102 \%$, meaning that there were more wireless devices than the total population. ${ }^{1}$ Whilst smartphones do not account for all wireless devices, it is estimated over $75 \%$ of medical staff use a smartphone. ${ }^{2}$

Varied clinical uses of smartphones are being increasingly documented in the medical literature. The assessment of wounds by picture messaging has become ubiquitous amongst plastic surgeons, and studies have found promising results. ${ }^{3}$ Communication between medical staff and hospitals has also been facilitated greatly with the use of "push email' and notifications; in addition to certain hospitals integrating paging systems with smartphone notifications. ${ }^{4,5}$ With the advent of custom designed applications, smartphone use has rapidly expanded and a number of specialties are producing innovative applications relevant to their own specialty, such as orthopaedic decision support applications ${ }^{6}$, offsite radiology access ${ }^{7}$, anaesthetic techniques ${ }^{8}$ or infectious disease physicians tracking epidemics ${ }^{9}$ to name a few. With continued innovation, medical applications will continue to be developed at an exponential rate. Storage of reference materials is another area which has become popularized, with many a medical student's heavy textbooks being traded for electronic textbooks accessible in the palm of their hand. ${ }^{10}$

Whilst the smartphone has been the catalyst for the transition of E-health to mobile health (mHealth), various other mobile technologies have been introduced to the market which show promise. Tablets are now becoming mainstream with the advent of the Apple iPad, which finally took tablets from a specialist item, to something that many people find essential. Medical uses of iPads are rapidly expanding, with examples such as patient education material, reference material storage, medical education 11 , and even use in research projects (as exemplified in a case report in this issue of our journal). Advances in technology have allowed specialized devices to be produced which are either mobile equivalents of large cumbersome pieces of equipment, such as ultrasound scanners, devices for deep venous thrombosis (DVT) prophylaxis ${ }^{12}$, or devices which interface with smartphones, such as blood sugar level (BSL) monitors which can monitor and transmit results to physicians $^{13}$. 
Whilst all of these developments amongst mobile technology show great promise, it is of utmost importance that the rigors of evidence based medicine are applied. Without a strong evidence base to support a product or application, one needs to be cautious about its use. New pharmaceutical products undergo demanding testing, and their efficacy needs to be proved through appropriate studies. Similarly, new technologies should also be tested through the scientific process, and their value needs to be carefully documented. Currently, there exists a gap in the literature, and no medical journals focus on documenting developments in the field of mobile technology. The launch of the Journal of Mobile Technology in Medicine represents an opportunity for doctors to be kept up to date with quality peer reviewed research articles, and provides an avenue for researchers to publish articles which will shape the field of mobile technology and its application to medicine.

\section{References}

1. CTIA. US Wireless Quick Facts. http://www.ctia.org/consumer_info/index.cfm/AID/10323. 2011.

2. SandlotSolutions. $75 \%$ of Physicians Use iPad or iPhone, Survey Shows. http://www.sandlotsolutions.com/knowledgeresources/industry-news-items/2011/05/09/75-physiciansuse-ipad-or-iphone-survey-shows. 2011.

3. Hsieh C-H, Tsai H-H, Yin J-W, Chen C-Y, Yang JC-S, Jeng S-F. Teleconsultation with the mobile cameraphone in digital soft-tissue injury: a feasibility study. Plast. Reconstr. Surg. 2004 Dec.;114(7):1776-1782.

4. Wu RC, Morra D, Quan S, Lai S, Zanjani S, Abrams $\mathrm{H}$, et al. The use of smartphones for clinical communication on internal medicine wards. J Hosp Med. 2010 Oct.;5(9):553-559.

5. Voalte. http://www.voalte.com. 2012.
6. Franko OI. Smartphone Apps for Orthopaedic Surgeons. Clin Orthop Relat Res. 2011 May 6;469(7):20422048.

7. Dala-Ali BM, Lloyd MA, Al-Abed Y. The uses of the iPhone for surgeons. The Surgeon. Elsevier Ltd; 2011 Feb. 1;9(1):44-48.

8. Rosser BA, Eccleston C. Smartphone applications for pain management. Journal of Telemedicine and Telecare. 2011 Aug. 26;17(6):308-312.

9. Oehler RL, Smith K, Toney JF. Infectious Diseases Resources for the iPhone. CLIN INFECT DIS. 2010 May;50(9):1268-1274.

10. Franko OI, Tirrell TF. Smartphone App Use Among Medical Providers in ACGME Training Programs. J Med Syst. 2011 Nov. 4.

11. Herd CL, Epperly R, Cox KM. Technology: Clinical and Technological Innovations: Use of the Apple iPad in Clinical Supervision. Perspectives on Administration and Supervision. 2011 Oct. 12;21(3):112-116.

12. Tucker A, Maass A, Bain D, Chen L. Augmentation of venous, arterial and microvascular blood supply in the leg by isometric neuromuscular stimulation via the peroneal nerve. Journal of Angiology: 2010.

13. Melanson D. Sanofi-Aventis debuts iBGStar blood glucose meter for iPhone. http://www.engadget.com/2010/09/21/sanofi-aventisdebuts-ibgstar-blood-glucose-meter-for-iphone/. 2010.

\section{Disclaimer}

All product names, logos, brands and other trademarks featured or referred to within the Journal of Mobile Technology in Medicine e-publication remain the property of their respective trademark holders.

These trademark holders are not affiliated with the Journal of Mobile Technology in Medicine, and do not sponsor or endorse this journal. 